\title{
La nación española en la transición política a la democracia: recuperemos la memoria y el auténtico relato de la transición ${ }^{1}$
}

\section{The Spanish Nation in the Political Transition to Democracy: Let us Recover the Memory and the Authentic Story of the Transition}

\author{
Carlos Vidal Prado ${ }^{2}$ \\ Universidad Nacional de Educación a Distancia (España) \\ ORCID: https://orcid.org/0000-0002-5204-027X
}

Recibido: 07-06-2021

Aceptado: 19-06-2021

\section{Resumen}

En este trabajo se intenta combatir el falso relato sobre la transición española a la democracia que se pretende imponer por parte de algunos sectores. Para ello, se destaca el papel que tuvo la sociedad española, que fue la que impulsó el cambio, que pudo materializarse gracias a una clase política que supo encauzar lo que los ciudadanos querían. Se analizan con detalle dos de los hitos principales de la transición: la elaboración de la Ley para la Reforma Política de 1976 y la configuración del régimen electoral, tanto en dicha Ley como en el Decreto-Ley de normas electorales de 1977. Se reivindica la auténtica memoria de la transición, que no debe excluirse de la memoria democrática de la nación española.

\footnotetext{
${ }^{1}$ Este Trabajo es resultado de proyecto de investigación financiado por el Ministerio de Ciencia, Innovación y Universidades RTI2018-096103-B-100 "Enseñar la Constitución. Educar en Democracia", aprobado en la Convocatoria I+D+i "Retos de investigación" correspondiente a 2018.

${ }^{2}$ (cvidal@der.uned.es). Catedrático de Derecho Constitucional de la Universidad Nacional de Educación a Distancia. Vocal de la Junta Electoral Central. Becario de la Fundación Alexander von Humboldt. Académico correspondiente de la Real Academia de Jurisprudencia y Legislación. Director Ejecutivo de la Revista de Derecho Político. Autor de doce monografías y más de cien publicaciones sobre diversos campos: sistema electoral, derechos fundamentales (especialmente los derechos educativos), relaciones entre jurisdicciones nacionales y Tribunal de Justicia de las Comunidades Europeas, Estado autonómico español. Entre sus trabajos más relevantes: El derecho a la educación en España. Bases constitucionales para el acuerdo y cuestiones controvertidas (Marcial Pons, 2017), El sistema electoral alemán y su posible aplicación en España (Tirant lo Blanch, 2012); "Spain", en Thiel, M., The 'Militant Democracy' Principle in Modern Democracies (Ashgate, 2009).
} 
Palabras-clave: Transición política española, Ley para la Reforma Política, proceso constituyente español

\begin{abstract}
This paper attempts to combat the false narrative about the Spanish transition to democracy that some sectors are trying to impose. To this end, the role played by Spanish society stands out, which was the one that drove the change, which could materialize thanks to a political class that knew how to channel what the citizens wanted. Two of the main milestones of the transition are analysed in detail: the drafting of the Political Reform Act of 1976 and the configuration of the electoral system, both in that Law and in the 1977 DecreeLaw on Electoral Regulations. The true memory of the transition is claimed, which must not be excluded from the democratic memory of the Spanish nation.
\end{abstract}

Keywords: Spanish Political Transition, Law for Political Reform, Spanish Constituent Process

\title{
1. La memoria democrática no puede consistir en la reescritura sesgada de la historia
}

A pesar de la indudable relevancia histórica que tiene la transición política española, el relato dominante en los últimos tiempos busca una deslegitimación del proceso, intentando socavar los cimientos del vigente sistema democrático español. Bajo la excusa de la necesidad de los cambios, se plantea más bien una alternativa rupturista que nos asoma a un peligroso precipicio que deberíamos evitar.

Resulta preocupante que el discurso político esté dominado por grupos que no valoran el meritorio y ejemplar proceso democratizador español, para hacer hincapié exclusivamente en los defectos, grupos que además son muy activos en la difusión de sus ideas por todos los medios, utilizando las nuevas tecnologías y las redes sociales. De este modo están contribuyendo a que la población joven, y en general quienes no han vivido esa época, tengan una idea de la transición muy diferente a la realidad. Además, nuestros jóvenes no tienen acceso, en su formación previa a la Universidad, a los conocimientos mínimos básicos sobre nuestro sistema constitucional. Al margen de que sea necesaria o no una asignatura específica de educación cívica y en valores democráticos, debería existir un mayor peso de estos contenidos de modo transversal, en diferentes materias. Sin embargo, encontramos una gran diversidad de enfoques entre comunidades autónomas y sólo se abordan estas cuestiones tangencialmente, por lo que los mensajes que la población de menor edad 
recibe no parecen suficientes para verificar o contrarrestar las informaciones manipuladas que absorben por otros medios.

Todo ello provoca una lamentable desafección de un sector de la ciudadanía, en torno al concepto de "régimen del 78", que es la expresión que utilizan en sentido negativo tanto los detractores de la transición (algunos grupos políticos populistas y/o antisistema) como quienes por otros motivos buscan atacar el sistema democrático español: singularmente los movimientos separatistas catalán y vasco, así como algunos partidos separatistas de otras regiones de España ${ }^{3}$. Se trata de llevar a cabo una relectura de la época, construir un relato que lleva a mirar con desconfianza absolutamente todo lo realizado, lo cual se vincula en parte a un revisionismo histórico camuflado a veces bajo la idea de "memoria histórica" o "memoria democrática", y que incluso tiene reflejo en algunas propuestas legislativas actualmente en trámite. Así, éstas incluyen dentro del periodo que debe "revisarse" no solamente la Guerra civil y el franquismo, sino incluso años en los que los gobiernos españoles ya eran democráticos, como sucede después de las elecciones de $1977^{4}$.

Es decir, los hijos y los nietos de quienes supieron ser generosos durante la transición española a la democracia tratan de rectificar esa grandeza de miras y ese ánimo conciliador, para imponer ahora, más de cuarenta años después, una visión sectaria, reducida y sesgada de lo que realmente ocurrió en esos años. Quienes no vivieron (y sufrieron) el franquismo pretenden reescribir la historia y romper el equilibrio alcanzado en nuestro proceso constituyente, que tanto tiempo y esfuerzo costó. No en vano Alfonso Guerra se ha referido de modo constante a la Constitución española de 1978 como "acta de paz", utilizando un término que se ha empleado por

3 "En su pasión por derrumbar nuestra democracia reconocida en la Constitución de 1978, los representantes de movimientos antisistema, singularmente agrupados en Podemos, se rindieron a la tentación del compadreo con los separatistas, provocando una fisura en sus propias filas", decía Juan Luis Cebrián en el artículo titulado "El régimen del 78", publicado en El País, el 27 de octubre de 2017.

Disponible en: https://elpais.com/elpais/2017/10/27/opinion/1509133295 310894.html

${ }^{4}$ El Anteproyecto de Ley de Memoria democrática dedica el Título I a las víctimas, e incluye dentro de este concepto a todas las víctimas "durante el período comprendido entre el golpe de Estado de 18 de julio de 1936, la Guerra de España y la Dictadura franquista hasta la promulgación de la Constitución Española de 1978" (art. 1 del Anteproyecto). Es decir, también se deja la sombra de sospecha sobre la posible "represión o persecución" en los primeros años de gobiernos democráticos (1977/1978). Nótese también cómo se evita incluso el término Guerra civil, y se le denomina "Guerra de España", asumiendo la terminología que utilizó la República española ante la Sociedad de Naciones, como si solamente hubiese habido un bando en la contienda, y la responsabilidad de la Guerra fuese exclusivamente de uno de esos bandos, ignorando la violencia previa existente también en el bando republicano contra sectores de la derecha y de la Iglesia. Anteproyecto disponible en:

https://www.mpr.gob.es/servicios/participacion/Documents/APL\%20Memoria\%20 Democr\%C3\%A1tica.pdf

${ }^{5}$ Alfonso Guerra utilizó este término de manera profusa en las múltiples actividades que se realizaron con motivo del 40 aniversario de la Constitución. Por ejemplo, en la entrega de la medalla del Gobierno de Aragón a los ponentes constitucionales (cfr.

https://www.elperiodicodearagon.com/aragon/2018/11/26/aragon-conmemora-40-aniversarioconstitucion-46709051.html ). Lo ha publicado posteriormente en su contribución "La Constitución 
otros protagonistas de la transición ${ }^{6}$ y también en el ámbito académico ${ }^{7}$. Ignorando esta realidad, una parte de la actual clase política ha contribuido y contribuye a esta ceremonia de la confusión. De hecho, es frecuente escuchar a quienes sí vivieron aquella época y siguen hoy entre nosotros, cómo el paso de los años ha ido engrandeciendo las figuras de los políticos que pilotaron y protagonizaron la transición, por su generosidad, su altura de miras, su convencimiento para alcanzar un proyecto compartido, por lograr acuerdos y consensos. Algo que, por desgracia, queda muy lejos de lo que hoy presenciamos en el día a día de nuestra vida política.

En los primeros años de democracia ya se había dado, tras el entusiasmo inicial, un cierto desencanto en la población, que los politólogos y sociólogos suelen describir como habitual en las transiciones de regímenes totalitarios a la democracia. Pero después de la victoria socialista en 1982, la situación cambió radicalmente. Como han estudiado Linz y Montero, entre otros, esos resultados y el posterior gobierno socialista de Felipe González tuvieron "los efectos combinados de lograr la consolidación democrática y la desaparición de las preocupaciones colectivas sobre el desencanto"8. Por ello, el régimen democrático español gozó de una legitimidad muy elevada desde sus inicios, en contra del relato que algunos quieren hoy imponer.

Es evidente que en la transición hubo errores, y que las secuelas de éstos deben ser corregidas. Es verdad que la Constitución tiene defectos y necesita una actualización, por eso es necesario afrontar una reforma. Pero no una reforma para destruirla, para derrumbar lo construido. Hay un término medio entre el inmovilismo y la ruptura. En parte es lo que describía Molinero, al hablar sobre cómo entienden unos y otros la transición: "para unos en aquel proceso se selló un pacto que debe ser inamovible, dado que en los aspectos más sensibles de la estructuración política se alcanzó el techo del consenso. Para otros es imprescindible una segunda Transición porque en los años setenta no fue posible conseguir cambios más profundos en esos mismos aspectos", siempre vinculando esas diversas lecturas a proyectos políticos o sociales actuales ${ }^{9}$.

del consenso", en Pendás, Benigno (dir.) España constitucional (1978-2018). Trayectorias y perspectivas, Centro de Estudios Políticos y Constitucionales, Madrid, 2018, tomo I, p. 92.

${ }^{6}$ Lo hace también Fernando Álvarez de Miranda en el artículo titulado "El legítimo orgullo de los libres e iguales", Diario El Mundo, 6 de diciembre de 2018. Disponible en: https://www.elmundo.es/ opinion/2018/12/06/5c081bb0fc6c83c4468b47b2.html

7 Tajadura Tejada, J., "La reforma constitucional como problema", en Estudios Culturales Hispánicos, 1 / 2020, pp. 91-113 (pp. 93 y ss). Castellà Andreu, J.M., "1978-2018: la Constitución del consenso en crisis", en Letras Libres, diciembre 2018, disponible en; https://www.letraslibres.com/ espana-mexico/politica/1978-2018-la-constitucion-del-consenso-en-crisis

${ }^{8}$ Montero, J.R., "Sobre la democracia en España: legitimidad, apoyos institucionales y significados", Estudios = Working papers / Instituto Juan March de Estudios e Investigaciones, Centro de Estudios Avanzados en Ciencias Sociales 1992/39. Disponible en: https://digital.march.es/fedora/objects/fjmpub:799/datastreams/OBJ/content Vid. también Linz, J.J., Montero, J.R., Crisis y cambio: electores y partidos en la España de los años ochenta, Centro de Estudios Constitucionales, 1986.

9 Molinero Ruiz, C., "Treinta años después, la transición revisada", en Molinero Ruiz, Carmen (Ed.), La transición treinta años después, Barcelona, Península, 2006, p. 9. 
Pero, de igual modo que el debate (en los últimos años del franquismo y en los meses inmediatamente posteriores a la muerte del dictador) se planteó en términos de reforma o ruptura, ahora algunos pretenden que, en lugar de reformar aquellos aspectos de nuestro sistema político que requieren mejora, se rompa con el sistema, incluso que se cambie de sistema, sin saber muy bien qué opción es la que se defiende como alternativa. La ruptura que se consiguió evitar entonces para impedir la fragmentación de España parece que se quiere imponer ahora ¿para volver a una Constitución de parte, como en nuestra experiencia histórica hemos tenido que sufrir tantas veces?

Es cierto que también ha podido influir en este movimiento político el hecho de que nuestra Constitución no se haya reformado en ningún aspecto sustancial en más de cuarenta años (las dos reformas que se han acometido son puntuales y, en el primer caso, mínima). Cuanto más se tarda en reformar una Constitución, más riesgo de ruptura existe. Pero esto no debe llevar a concluir que ha de cambiarse por completo la Constitución.

Lo que se constata, en todo caso, es que la falta de conocimiento de lo que realmente sucedió durante la transición y la sustitución por una información y un relato paralelo alejado de la verdad están influyendo en la percepción que de ese proceso tiene la sociedad española actual, especialmente la población más joven. En las series del Banco de Datos del CIS podemos comprobar cómo la evolución de la respuesta positiva a la pregunta “¿Cree Ud. que la forma en que se llevó a cabo la transición a la democracia constituye hoy en día un motivo de orgullo para los/as españoles/as?", ha pasado de rondar el $80 \%$ desde los años ochenta (con su punto más alto en 2000 , con un $86 \%$ ), hasta comenzar una bajada continuada desde 2003, que en 2018 situaba ese porcentaje en un $67,3 \%$. En paralelo, la respuesta negativa a dicha pregunta ha pasado de no llegar apenas al $10 \%$ hasta el año 2008 , a situarse en un $22 \%$ diez años más tarde ${ }^{10}$. En otra encuesta realizada en 2014 por GAD3 para la Fundación "Transición Española", que discriminaba por edades, se puede comprobar cómo el sentimiento de orgullo sobre la transición es de un 59,6\% globalmente considerado, pero se eleva hasta el $64,1 \%$ en la franja de edad de 45 años en adelante y es de un $53,8 \%$ entre quienes tienen 18 a 44 años ${ }^{11}$.

No pretendo en este trabajo abordar la ingente tarea de elaborar un relato auténtico de la transición. Hay muchísima bibliografía, mucha documentación: se trata de una cuestión muy analizada desde el punto de vista académico e investigador (Raymond Carr llegó a decir que la transición española fue un "festín para los politólogos"12). Pero sí me gustaría hacer hincapié en

${ }^{10}$ CIS, SERIES-BANCOS DE DATOS DEL CIS, A.3.07.02.008. Opinión acerca de si la transición política es motivo de orgullo para los españoles. Disponible en http://www.analisis.cis.es/cisdb.jsp

${ }_{11}$ Encuesta disponible en la página web de la Fundación: http://www.transicion.org/Destacados flash/encuestaCAD3/EN_140000 Transicion_resultados.pdf

${ }^{12}$ Carr, Raymond, El rostro cambiante de Clío: Ensayos. España-Gran Bretaña, Biblioteca Nueva, 
determinados aspectos que engrandecen el proceso, con sus luces y sus sombras, para reivindicar con esos ejemplos una lectura real y auténtica.

\section{EI decisivo papel de la sociedad española}

Uno de los elementos claves para entender el éxito de nuestra transición de la dictadura a la democracia es la sociedad española. Se trataba de una sociedad que, sobre todo a partir de los años sesenta, había visto crecer sus clases medias, pues económicamente el país se había empezado a recuperar después de unos lustros de gran carestía. Pero, junto a ello (o quizá precisamente a causa de ello), era una sociedad que desde el punto de vista político se iba alejando de los principios del régimen político autoritario, y se identificaba cada vez más con los regímenes democráticos de los países de nuestro entorno europeo. La clave, entonces, era que la clase política supiese ver esta realidad y lograse sintonizar con los deseos de cambio de los españoles.

Como dice con acierto Eloy García, la vida y la política española posteriores a 1939, "iban a ser reconstruidas o si se prefiere replantadas, desde raíces nuevas, esto es, sobre fundamentos que no tenían substancialmente puntos de continuidad genealógica con los supuestos vigentes antes de la guerra civil, ni en la sociedad ni en la política, ni en el Estado ni en las creencias, ni en la izquierda ni en la derecha" ${ }^{13}$. De hecho, se ha afirmado que en la España de Franco (al menos en las dos primeras décadas del régimen) no existía cultura política en el sentido de un "conjunto de ideas ampliamente compartidas sobre el carácter de la comunidad nacional (problema regional) ni las reglas del juego político (forma de Estado, forma de Gobierno, alcance de la participación, etc.)"14. No había, por tanto, ni una cultura política homogénea, ni siquiera una fragmentada. Si acaso había dos culturas políticas débilmente configuradas que se alineaban bien con el régimen, bien con la oposición, pero solamente entre las clases sociales más cultivadas intelectualmente.

Todo lo que estamos comentando, la situación general de la población y la sociedad española, "terminaría resultando determinante, entre otras cosas, para entender qué movería a los protagonistas del proceso de transición política a actuar desde la realidad de los hechos y no desde una memoria de la que no eran herederos y, en consecuencia, a la que no se sentían vinculados"15.

\footnotetext{
Madrid, 2005, p. 295

${ }^{13}$ García López, E., “Apuntes para una relectura heterodoxa de la transición política española”, en Estudios de Deusto, Vol. 61/1, Bilbao, Enero-Junio 2013, p. 131.

${ }^{14}$ López Pintor, R. "El estado de la opinión pública española y la transición a la democracia”, en Revista Española de Investigaciones Sociológicas, núm. 13, 1981, p. 14.

${ }^{15}$ García López, E., "Apuntes para una relectura heterodoxa de la transición política española”, op. cit., p. 131.
}

Araucaria. Revista Iberoamericana de Filosofia, Política, Humanidades y Relaciones Internacionales, año $23, \mathrm{n}^{\circ} 47$. Segundo cuatrimestre de 2021. Pp. 255-278. ISSN 1575-6823 e-ISSN 2340-2199 https://dx.doi.org/10.12795/araucaria.2021.i47.12 
La España de 1975 no tenía nada que ver con la de 1936 o la de 1939. En 1969 en España no había "solución de continuidad histórica con la España anterior al conflicto. Aquella España no existía ya en tierra española”. El reto de la clase política era conectar con la sociedad, una sociedad que había crecido durante el franquismo, que rechazaba una revolución como la portuguesa, que quería un cambio pacífico en el que pasar a ser protagonista de su destino ("lo que en verdad sobrevivió a la vida del dictador terminó siendo la sociedad que él había creado"16). Por eso la transición política española, que sirvió de modelo a otras muchas (primero en Latinoamérica, luego en los países de la Europa del Este), fue un ejemplo de "cómo rearticular una Ciudad sin necesidad de anular, ni arruinar hasta los cimientos, la comunidad política precedente" 17 .

Encontramos ideas similares sobre esta cuestión en otros autores. Así, por ejemplo, Carmen Fernández-Miranda afirma que "el mismo cambio económico generó una sociedad distinta que, si bien valoraba la paz que había permitido su ascenso económico, y estaba dispuesta a esperar, tenía los ojos puestos en otros modelos existentes allende nuestras fronteras" 18 , ideas muy parecidas a las sostenidas por López Pintor ${ }^{19}$. Y, en esta misma línea, Manuel Ramírez subraya algunos rasgos que caracterizaban a esa sociedad: cierta secularización; despolitización y provocada apatía; pervivencia del trauma de la guerra civil y suspicacia ante los problemas de orden público (que se identificaba con la paz y el desarrollo económico $)^{20}$.

Además, esa "secularización" de la que habla Ramírez tiene que ver con la actitud de la Iglesia, uno de los elementos sustentadores del régimen franquista en los primeros años, y que a partir sobre todo del Concilio Vaticano II y su defensa de la libertad religiosa se va a alejando cada vez más del franquismo. Efectivamente, una vez que, en la Declaración Dignitatis Humanae, el Concilio "declara que la persona humana tiene derecho a la libertad religiosa" conflicto con el confesionalismo del régimen franquista es evidente, y lo que la Iglesia y los propios fieles católicos españoles empiezan a preguntarse es: si hay libertad religiosa, ¿por qué no libertad política y sindical? Empezaron a surgir sacerdotes críticos con el régimen, organizaciones obreras católicas que funcionaban como embriones de sindicatos. Incluso en 1970 la Conferencia

${ }^{16}$ Ibid., p. 135.

${ }^{17}$ Ibid., p. 136.

18 Fernández-Miranda Campoamor, C., "Consideraciones en torno a los antecedentes de la transición política española”, En Boletín de la Facultad de Derecho UNED, núms. 8-9, 1995, p. 345.

${ }^{19}$ López Pintor, R., "Los condicionamientos socioeconómicos de la acción política en la transición democrática", en Revista de Investigaciones Sociológicas, núm. 15, 1981, p.15 y ss. 112.

${ }^{20}$ Ramírez, M., España. 1939-1975. Régimen político e ideología. Ed. Labor. Barcelona 1978, p.

${ }^{21}$ Número 2 de la Declaración Dignitatis Humanae, sobre la libertad religiosa, de 7 de diciembre del año 1965. Disponible en: https://www.vatican.va/archive/hist_councils/ii_vatican_council/ documents/vat-ii decl 19651207 dignitatis-humanae sp.html

Araucaria. Revista Iberoamericana de Filosofía, Política, Humanidades y Relaciones Internacionales, año $23, \mathrm{n}^{\circ} 47$. Segundo cuatrimestre de 2021. Pp. 255-278. ISSN 1575-6823 e-ISSN 2340-2199 https://dx.doi.org/10.12795/araucaria.2021.i47.12 
Episcopal criticó la Ley Sindical y se fueron produciendo situaciones de tensión cada vez más frecuentes ${ }^{22}$.

La transformación de la sociedad española comenzó en los años sesenta, de acuerdo con lo que especialistas en sociología y en opinión pública han acreditado: "en aquellos años (1960-1975) comenzó a fraguarse una sociedad civil que dotó a los ciudadanos de los recursos necesarios para poder pensar en sí mismos como sujetos de derechos y protagonistas de la esfera pública, que más tarde resultó ser fundamental para el éxito del proceso del cambio político hacia la democracia"23. Los españoles se habían hecho, en los últimos años del franquismo, "mucho más tolerantes, menos inclinados a tomar y apoyar posiciones extremas de cualquier signo, más conscientes de sus derechos, y más interesados en participar en política. Este enorme cambio producido en la sociedad, junto con la existencia de una economía de mercado que estaba ofertando los bienes y servicios que la gente deseaba consumir y los puestos de trabajo que esta requería, son, sin duda los factores del trasfondo fundamental que hizo posible la transición rápida y pacífica a la democracia en España"24.

Es significativo también constatar, en las encuestas de la época, cómo se va inclinando la mayoría de la sociedad cada vez más hacia las actitudes democráticas de gobierno. En 1966 solamente un 35\% de los encuestados preferían que se tomasen las decisiones por personas elegidas por el pueblo, y en 1976 ese porcentaje se eleva hasta el 78\%. En la encuesta nacional de 1976 se pone asimismo de manifiesto cómo cada vez se otorga menos importancia a la paz, el orden y la tradición y más a la justicia, la libertad y la democracia ${ }^{25}$.

En este contexto, influyó también una cierta apertura en el ámbito de los medios de comunicación a partir de la Ley de Prensa de 1966, que posibilitó el surgimiento de nuevos periódicos a inicios de los años sesenta, y que sirvió para dotar de un cierto pluralismo incluso ya durante los últimos años del franquismo, que se acentuó una vez muerto el dictador. Este es un rasgo en el que, por ejemplo, se distingue la situación de nuestro país de la de otros procesos de transición a la democracia como los de los países de la Europa del Este $^{26}$.

${ }^{22}$ Torres del Moral, A., Constitucionalismo histórico español, $9^{\mathrm{a}}$. edición, Ed. Universitas, Madrid, 2018, p. 258.

${ }^{23}$ Hernández Sánchez, A., "La opinión pública española en la transición del franquismo a la democracia", Revista de Investigaciones Políticas y Sociológicas, Vol. 9, núm. 1, 2010, pp. 39-69. (cita de p. 40). Confirma también la tesis de Ramírez sobre la tendencia a la secularización de la sociedad.

${ }^{24}$ Casas Pardo, J., "La transición política española a la democracia. Un enfoque de Public Choice", en Historia Contemporánea, núm. 27, 2003, p. 896.

${ }^{25}$ Son datos que utiliza López Pintor, del Instituto de la Opinión Pública (de 1966 y 1976), de Consulta, S. A. (1974), y fueron publicados en Cambio 16, 3 de junio de 1974. Cfr. López Pintor, R. "El estado de la opinión pública española y la transición a la democracia", en Revista Española de Investigaciones Sociológicas, núm. 13, 1981, pp. 18 y siguientes.

${ }^{26}$ Se analiza esta cuestión en Montero, M., Rodríguez-Virgili, J., García-Ortega, C., "La 
La crisis del petróleo de 1973 provocó una depresión económica en todo el mundo, que dejó sentir sus efectos en España con cierto retraso, sobre todo después de la muerte de Franco. Hacía falta caminar hacia una situación que procurase prosperidad a la sociedad española: "era muy probable que la misma sociedad que aspiraba a perpetuar su status quo, estuviera decidida a abrazar la Democracia, siempre y cuando ello no supusiera ruptura del modelo social. Faltaba por saber si la oposición estaría dispuesta a entrar en el juego de conservar la sociedad y cambiar la política. Y esa fue justamente la tarea que asumió de manera inmediata Adolfo Suárez"27.

La faena más complicada para Suárez era convencer a la oposición para implicarse en el proceso, puesto que no confiaban en sus verdaderos deseos de reforma, y suponían una capacidad de resistencia al propio régimen que no era realmente así. Esta incredulidad era prácticamente unánime en una oposición que, por ver imposible la reforma desde dentro, optaba claramente por una ruptura. La oposición atribuía más poder del que realmente tenía al "búnker", es decir, a los sectores más radicales e inmovilistas del régimen franquista, y no creían que el Ejército estuviese dispuesto a tolerar una reforma hacia la democracia. El mayor problema para Suárez, sin embargo, no era superar las dificultades internas dentro del franquismo, sino "conseguir implicar en la transformación a una oposición democrática que vacilaba ante la posibilidad de llegar a acuerdos que le dieran su participación efectiva en la conducción política"28.

Todo ello se fue consiguiendo, como ponen de relieve las palabras de Ollero en el Congreso organizado por el CITEP en noviembre de 1976. Así, sostenía que la variación de la situación en pocos meses, desde la muerte del dictador, fue provocada "por la actitud, serena e incluso templada, pero continua y bien significativa, del pueblo español y la acción, hasta ahora al menos compenetrada y unida, de la Oposición democrática. Lo que no impide valorar cauta pero positivamente la actitud de quienes desde las propias estructuras del Régimen se han predispuesto a encajar esa realidad sin estridencias antagonistas e incluso con propósito de colaboración" 29 .

construcción mediática de la comunidad política. La prensa en la transición española a la democracia", en Palabra Clave, vol. 11, núm. 3, diciembre 2008, pp. 293-309.

${ }^{27}$ García López, E., “Apuntes para una relectura heterodoxa de la transición política española”, op. cit., p. 145.

${ }^{28}$ Ibid., p. 146.

${ }^{29}$ Ollero, C., "El Contexto Político de unas Elecciones en España" (conferencia pronunciada el 18 de noviembre de 1976), en VV.AA., Ley Electoral y consecuencias políticas, CITEP, Madrid, 1977, p. 6.

Araucaria. Revista Iberoamericana de Filosofia, Política, Humanidades y Relaciones Internacionales, año $23, \mathrm{n}^{\circ} 47$. Segundo cuatrimestre de 2021. Pp. 255-278. ISSN 1575-6823 e-ISSN 2340-2199 https://dx.doi.org/10.12795/araucaria.2021.i47.12 


\section{EI "milagro" de la Ley para la Reforma Política}

La propia tramitación de la Ley para la Reforma Política, como refleja el libro que le dedicó el profesor Lucas Verdú ${ }^{30}$, es un claro ejemplo de las dudas de la oposición, que no se creía que la Ley pudiese llegar a cumplir su función y dudaban de la sinceridad de los actos de Suárez. El éxito de esta empresa, unido a otros elementos, singularmente el Decreto Ley Electoral de 1977, y hechos como la legalización del PCE, consiguieron convencer a prácticamente todos. Como afirma Tusell, el resultado final estuvo más cerca de lo que postulaba la oposición rupturista y el procedimiento seguido fue el preconizado por las posiciones reformistas ${ }^{31}$. Torres del Moral habla de una "doble reforma o de una reforma de doble fase: la introducida por la Ley para la Reforma Política y la que, en aplicación de ella, elaboraron las Cortes democráticas: la Constitución vigente". La Ley de Reforma Política pretendía allanar los obstáculos para conseguir un nuevo cuerpo legislador (constituyente) legitimado democráticamente ${ }^{32}$.

La Ley para la Reforma Política fue calificada por Cavero como "ley constitucional de transacción para la transición"33. Lucas Verdú matiza esta definición, y en el mencionado libro viene a reflejar lo que era el sentimiento de muchas personas que ansiaban la llegada de la democracia, pero desconfiaban de los verdaderos propósitos de Suárez. Reconoce que la singularidad de la octava ley fundamental era que constituía una medida política excepcional. Pero solamente daría paso al Derecho constitucional de la democracia liberal "si el gobierno -cosa que hasta ahora no ha hecho- transige con la oposición" ${ }^{34}$. Llega a decir que "es innatural que la no democracia instaure la democracia", y concluye que el "destino probable" del proyecto Suárez "será desaparecer tras las modificaciones que realicen las futuras Cortes en el orden fundamental. Será, pues, una Ley Fundamental provisional, jaunque parezca paradójico!" 35 .

${ }^{30}$ Lucas Verdú, P., La octava Ley Fundamental. Crítica jurídico-política de la Reforma Suárez, Tecnos, Madrid, 1976.

31 Tusell. J., La transición española a la democracia, Publicado por Historia 16, 1991.

32 Torres del Moral, A., Principios de Derecho Constitucional Español, tomo 1, 6 ${ }^{\text {a }}$ edición, 2010, Servicio de Publicaciones de la Universidad Complutense, p.30. No procede que nos detengamos aquí en el proceso de elaboración del proyecto de Ley, sobre el que mucho se ha escrito. Permítaseme mencionar, en todo caso, una obra que considero esencial para comprender la dificultad de la empresa: Fernández-Miranda, P. y Fernández-Miranda, A., Lo que el Rey me ha pedido. Torcuato FernándezMiranda y la reforma política, Plaza y Janés, 1995. Una reconstrucción más reciente, que recoge abundante bibliografía sobre la cuestión, puede verse en Cebrián, E., Contreras Casado, M., "La ley para la Reforma Política: memoria y legitimidad en los inicios de la transición española a la democracia”, en Revista de Estudios Políticos (nueva época), Núm. 168, Madrid, abril-junio (2015), pp. 77-114. DOI: http://dx.doi.org/10.18042/cepc/rep.168.03

33 Cavero, I., "Soberanía popular y elecciones para constituyentes", en Informaciones Políticas, Revista semanal de Politica nacional y extranjera, núm. 69, 18 de septiembre de 1976.

34 Lucas Verdú, P., La octava Ley Fundamental. Crítica jurídico-politica de la Reforma Suárez, Tecnos, Madrid, 1976, p. 74.

35 Ibid., p. 75.

Araucaria. Revista Iberoamericana de Filosofía, Politica, Humanidades y Relaciones Internacionales, año $23, \mathrm{n}^{\circ} 47$. Segundo cuatrimestre de 2021. Pp. 255-278. ISSN 1575-6823 e-ISSN 2340-2199 https://dx.doi.org/10.12795/araucaria.2021.i47.12 
La crítica de Lucas Verdú a la Ley para la Reforma Política es demoledora, básicamente porque entiende que un régimen autoritario no puede dar paso, por sí mismo, a un régimen democrático. Y encuentra matices autoritarios en casi todos los puntos del texto, como por ejemplo en el propio proceso de reforma previsto en el Proyecto de Ley impulsado por Suárez ("está condicionado por residuos y trabas autoritarias" ${ }^{\prime 36}$, dice). Considera paradójico el proyecto de Ley, incoherente con el resto de las leyes fundamentales franquistas, aunque reconoce que el lenguaje es el propio del Estado liberal de Derecho (y precisamente por esto no está en coherencia con lo anterior), si bien, a continuación, dice que no se ajusta "ni siquiera mínimamente, al contenido y forma del Estado democrático de Derecho" 37 .

En realidad, lo que existe es suma desconfianza hacia el proceso. De hecho, se nota un cambio de tono radical entre el contenido del libro y el de la apostilla final, escrita en el momento en que se estaban corrigiendo las pruebas de imprenta del volumen, que coincidió con la aprobación de la Ley de Reforma Política "por abrumadora mayoría”, como dice el propio Lucas Verdú. En esas 7 páginas ("Apostilla sobre la aprobación por las Cortes de la Ley de Reforma Suárez") se reconoce: a) el éxito indiscutible del Presidente Suárez; b) que los debates se asemejaron, por primera vez, a los de los otros parlamentos europeos, y c) que la clase política postfranquista comprendió que era el único camino que les quedaba. Lo que se percibe al leer estas líneas es que la desconfianza e incredulidad deja lugar a la sorpresa y la constatación del "milagro", pues la propia dictadura estaba dando paso a la democracia: el Gobierno Suárez, "realizando la voluntad del trono, pretende superar la contradicción de que sean los propios órganos franquistas los que disuelvan el franquismo", en palabras de Tierno en el prólogo del libro. Estos recelos se aprecian en los debates transcritos en el libro Ley electoral y consecuencias politicas, que recoge las conferencias y los debates posteriores del Congreso organizado por CITEP en Madrid, los mismos días en los que en la Cortes se aprobaba la Ley para la Reforma Política. Duverger subrayaba la dificultad de la empresa de pasar de una dictadura a una democracia, y manifestaba que si se conseguía "será un ejemplo para el mundo y será de extrema utilidad" 38 , además de reprochar a la oposición su desconfianza y que se negasen a admitir que desde el Gobierno Suárez se estaban dando pasos decisivos: "Si yo tuviera que escribir una historia del paso de España de la dictadura a la democracia, habría un capítulo donde yo felicitaría con bastante efusión al Gobierno y a las autoridades españolas y sería implacablemente duro con la oposición española" ${ }^{39}$. Se refería a la primera

\footnotetext{
${ }^{36}$ Ibid., p. 79.

${ }^{37}$ Ibid., p. 81.

${ }^{38}$ Duverger, M., "Sufragio universal y democracia", conferencia pronunciada el 18 de noviembre de 1976, en VV.AA., Ley Electoral y consecuencias políticas, CITEP, Madrid, 1977, p. 133.

39 Ibid., p.139 (también en la p. 138 hay algunos comentarios dirigidos a la oposición).
} 
fase, a la del proceso de elaboración de la Ley para la Reforma Política, y les instaba a que en la segunda fase, la de la celebración de elecciones, se aviniesen a pactar con el Gobierno las condiciones.

Esa incredulidad y desconfianza se percibe en la mayor parte de la oposición al régimen de Franco. García San Miguel lo expresa en la "Introducción" a su libro Teoría de la Transición, pues incluso él, que desde la oposición fue de los pocos que defendió la reforma y no la ruptura (llamaba "revolucionarios" a quienes defendían esta tesis ${ }^{40}$ ), pensaba que dicha reforma sería la de la "vía Arias"41, es decir, una reforma "moderadísima y llena de dificultades. Nunca creyó - expone en tercera persona, aunque hablando de sí mismo-que las cosas pudieran llegar tan lejos como las llevó luego Adolfo Suárez. Y por eso se equivocó al oponerse a aquellos sectores de la prensa que propugnaban una reforma en profundidad, aproximadamente como la que luego tuvo lugar. Tuvo que verlo para creerlo"

En esos años surgieron diversas propuestas reformistas en el ámbito académico, quizá la más cercana a las posiciones de García San Miguel fue la plasmada por Jorge de Esteban y sus colaboradores en el volumen Desarrollo Político y Constitución Española: se defendía aquí también la reforma desde dentro, respetando la legalidad, caminando hacia la democratización, pero -igual que el autor anterior- comparte un planteamiento pesimista y más inclinado a pensar que el proceso sea lento y laborioso ${ }^{43}$. En la misma línea se había pronunciado Ollero, que en sus propuestas defendía la necesidad de respetar una "servidumbre jurídico-formal" al ordenamiento vigente: "la utilización de las bases legales por mínimas que fueran que ese ordenamiento pareciera ofrecer como posibles" 44 .

${ }^{40}$ Es crítico con los rupturistas, porque ve poco probable el éxito: "La revolución frustrada consolida al poder y, en las condiciones actuales, las posibilidades de éxito de un intento revolucionario parecen escasas a nuestro entender". Habla en presente porque, aunque el texto se publicó en el libro, en el año 1981 (Teoría de la Transición. Un análisis del modelo español, 1973-1978, Editora Nacional, Madrid; la cita entrecomillada es de la p. 47), en realidad reproduce un artículo publicado en el número 1 de la Revista Sistema, en enero de 1973, con leves modificaciones.

${ }^{41}$ Lo explica con detalle en el capítulo segundo del libro ("Cambio político y oposición bajo el franquismo”, pp. 55-79), que reproduce un artículo publicado en la revista Sistema, número 4 (enero, 1974).

${ }^{42}$ García San Miguel, L., Teoría de la Transición. Un análisis del modelo español, 1973-1978, Editora Nacional, Madrid, 1981, p. 14.

${ }^{43}$ De Esteban, J., Varela, S., García Fernández, F.J., López Guerra, L., García Ruiz, J.J., Desarrollo Político y Constitución Española, Ariel, Barcelona, 1973. Jorge de Esteban elaboraría también un proyecto de bases para la Constitución, encargado por Felipe González en diciembre de 1976, y que recientemente ha publicado. Cfr. De Esteban. Jorge, "Proyecto de unas bases constitucionales para España”, en Pendás, Benigno (dir.) España constitucional (1978-2018). Trayectorias y perspectivas, Centro de Estudios Políticos y Constitucionales, Madrid, 2018, tomo I, pp. 193-218.

44 Ollero, C., "El Contexto Político de unas Elecciones en España" (conferencia pronunciada el 18 de noviembre de 1976), en VV.AA., Ley Electoral y consecuencias políticas, CITEP, Madrid, 1977, pp. 6 y 7.

Araucaria. Revista Iberoamericana de Filosofia, Política, Humanidades y Relaciones Internacionales, año $23, \mathrm{n}^{\circ} 47$. Segundo cuatrimestre de 2021. Pp. 255-278. ISSN 1575-6823 e-ISSN 2340-2199 https://dx.doi.org/10.12795/araucaria.2021.i47.12 
Si bien es cierto que el texto de la Ley para la Reforma Política es el que Suárez asume a partir de la propuesta de Torcuato Fernández-Miranda, entre algunos políticos y académicos que buscaban una solución jurídica había una "hoja de ruta" más o menos clara. Muchos se han atribuido la autoría de buena parte de las propuestas, pero no todos las publicaron. En este sentido, es sin duda relevante el mencionado volumen de Jorge de Esteban y sus colaboradores (cuyo origen es un dictamen que le encargan al profesor de Esteban un grupo de personas, al parecer vinculadas al Banco Urquijo, como él mismo ha narrado) ${ }^{45}$. La idea común era buscar una última Ley fundamental que reformase (y derogase o vaciase de contenido) todas las demás, y luego celebrar elecciones democráticas para después elaborar una Constitución.

Areilza narra en sus memorias un almuerzo en el club Siglo XXI el 10 de mayo de 1976 en el que ya se habló de esta vía, de un "pacto nacional" para una reforma sensata "que desemboque en un sistema democrático". Y afirma que "el calendario, hasta el ritmo, podrían mejorar notablemente si el pacto se logra". Más adelante dice: "Una Constitución nueva, ¿sería posible? Desde el punto de vista del respeto a la legalidad, desde luego. ¿Sería conveniente? Uno de los temas de la mesa redonda del pacto podría ser precisamente ese. La necesidad imprescindible de que España se dé una nueva Constitución"46.

García San Miguel sostiene la idea ya apuntada de que la sociedad ya estaba aspirando al objetivo de la democracia, y la transición debería basarse en trasladar al ámbito político lo que era ya un "pacto social". Muchos españoles habían vivido el franquismo, pero no habían tenido la oportunidad de manifestar o exteriorizar sus opiniones políticas, y estaban deseando hacerlo. En este proceso colaboraron los franquistas, que se unieron al pacto y que propiciaron la reforma en lugar de la ruptura.

Para resaltar la relevancia del papel de la sociedad, García López describe lo que sucedió durante el proceso de elaboración, tramitación y aprobación de la Ley de Reforma Política, y posteriormente durante el proceso constituyente, como "el primer supuesto de Poder Constituyente Evolutivo que conoce la historia. Una forma de operar de la vieja categoría concebida en la modernidad, en la que la continuidad en la estabilidad primó sobre la ruptura de fondo y las transformaciones radicales" ${ }^{\prime 7}$. La sociedad fue el motor principal, se mantuvo sin grandes cambios, y la clase política acertó a convertirse en el catalizador de esos deseos de la ciudadanía: "la labor constituyente quedó reducida a levantar

${ }^{45}$ De Esteban, Jorge, "La memoria de un desmemoriado", Diario El Mundo, 24 de agosto de 2020. Disponible en: https://www.elmundo.es/opinion/columnistas/2020/08/24/5f425c70fdddff $965 \mathrm{f} 8 \mathrm{~b} 45 \mathrm{f} 9$. $\underline{\mathrm{html}}$

${ }^{46}$ Areilza, J.M., Diario de un ministro de la Monarquía, Planeta, 1977 (hubo luego varias ediciones posteriores, pero esta fue la primera), pp. 175-176.

${ }^{47}$ García López, E., op. cit., p.151. Sobre el concepto de poder constituyente evolutivo, vid. García López, E., El Poder Constituyente Evolutivo en la Crisis de la Modernidad Política, Universidad Javeriana, Bogotá, 2011.

Araucaria. Revista Iberoamericana de Filosofia, Política, Humanidades y Relaciones Internacionales, año $23, \mathrm{n}^{\circ} 47$. Segundo cuatrimestre de 2021. Pp. 255-278. ISSN 1575-6823 e-ISSN 2340-2199 https://dx.doi.org/10.12795/araucaria.2021.i47.12 
sobre lo que ya se conocía, una nueva Ciudad Política que hiciera propios los cimientos del régimen precedente. Era la sociedad quien, en su deseo de continuar, había generado un cambio en la política, y no la idea política la que había creado un mundo nuevo"48.

Hoy parece como si ciertos sectores retornasen a la incredulidad de algunos antes de que Suárez iniciase con pie firme el proceso, pero ya no por lo que iba a venir (como sucedió entonces), sino para ignorar (e incluso negar) lo que realmente ocurrió, queriendo imponer la idea de que en realidad no hubo reforma, de que en todo momento los cambios estuvieron mediatizados y condicionados por el Ejército o la Iglesia, para que no fuesen verdaderos cambios. A base de negar la evidencia, de repetir mil veces las cosas que no fueron, no conseguirán alterar la historia, pero sí podemos llegar a tener el problema de que las nuevas generaciones escuchen y crean una versión y una visión de la transición absolutamente opuesta a la real. Por eso es necesario recuperar el relato fiel de los hechos y transmitirlo. Valen también para hoy los consejos que daba Duverger en el Congreso de CITEP reiteradamente mencionado: "Hay que borrar todos los recuerdos de la guerra civil. Se trata de construir la España hoy, y solo se podrá construir si se crean grandes partidos demócratas"49.

Por otro lado, algunas de las carencias del proyecto de Ley de Reforma Política que Lucas Verdú señalaba en su libro fueron solventadas en la tramitación del proyecto en las Cortes, como él mismo reconoce en la "apostilla" que hemos mencionado. Por ejemplo: (i) la inclusión de la referencia a los Derechos Fundamentales; (ii) el mayor nivel de detalle en el régimen electoral para la conformación del Congreso y Senado, que necesitará no obstante de un desarrollo acorde con los principios democráticos, que aclare el significado de expresiones como la de que en la elección basada en la representación proporcional "se aplicarán dispositivos correctores", sin explicar qué tipo de dispositivos serán. Cierto que, al menos, de la Ley se deduce que uno de los elementos será la barrera electoral (se "fijarán porcentajes mínimos de sufragio para acceder al Congreso"), pero no se aclara si esta barrera se aplicará a nivel nacional o en cada circunscripción, y esto suscita inquietud sobre la posibilidad de que los partidos regionalistas o nacionalistas, en el caso de una barrera a nivel nacional, puedan quedarse fuera, lo cual sería negativo para la evolución de la transición. "Sería imprudente exasperar - dice Lucas Verdú- a las corrientes dominantes en el País Vasco, en Galicia y en Cataluña aplicándoles 'dispositivos correctores', dada su justificada hipersensibilidad política"s0.

\footnotetext{
48 Ibid., p. 152.

49 Duverger, M., "Sufragio universal y democracia", debate posterior a la conferencia pronunciada el 18 de noviembre de 1976, en VV.AA., Ley Electoral y consecuencias políticas, CITEP, Madrid, 1977 , p.146.

50 Lucas Verdú, P., La octava Ley Fundamental. Crítica jurídico-politica de la Reforma Suárez, 
Quedaba camino por recorrer, y así concluía Lucas Verdú esta "Apostilla”: "una vez aprobada la Ley para la Reforma Política, el Gobierno, desembarazado del obstruccionismo reaccionario, debe negociar con la oposición la libre, transparente y democrática votación del próximo referéndum y, sobre todo, la Ley electoral para que el pueblo español pueda convivir pacíficamente, dentro de un sistema político auténticamente representativo que respete los derechos y libertades básicos, como establece el artículo 1, párrafo 2, de la Ley y establezca unas bases socioeconómicas justas" ${ }^{51}$. A este asunto dedicaremos el siguiente apartado.

\section{La relevancia de la Ley Electoral}

Sin duda, después de la Ley para la Reforma Política, la otra norma que iba a resultar decisiva era la que regulase el proceso electoral, desarrollando los elementos básicos ya incluidos en dicha Ley. Este es un aspecto esencial para la legitimidad democrática de las futuras Cortes, y debía negociarse con la oposición. Así lo recoge Lucas Verdú en la obra citada y lo reclamaban los políticos de la oposición, empezando por el propio José María Gil Robles ${ }^{52}$. La importancia que la Ley Electoral tenía para el proceso democratizador la resaltó gráficamente Duverger, al decir que "la Ley Electoral y el sufragio universal será el momento en que ustedes matarán el toro de la dictadura"53.

Aunque algunos se fijaban en el sistema electoral de la Segunda República, como decía Duverger no parecía adecuado: en España no había tradición democrática, "porque tradiciones que se han interrumpido desde hace 40 años ya no son tradiciones" ${ }^{54}$. En la propia elaboración de la Ley para la Reforma Política, uno de los principales objetos de negociación fue el sistema electoral, como pone de relieve Torres del Moral. La clase política franquista se inclinaba por el sistema mayoritario (Alianza Popular lo defendió, tanto en las Cortes franquistas como luego en las primeras Cortes democráticas, durante el proceso constituyente), porque "creían que podían encontrar ellos mayores facilidades". Sin embargo, la oposición reivindicaba la fórmula proporcional, para dar representación al mayor número posible de grupos políticos, y el

op. cit., p. 127. Sobre esta cuestión se debatió ampliamente en el Congreso de CITEP, como puede constatarse en el volumen ya citado.

51 Ibid., p. 128.

${ }^{52}$ Gil Robles, J.M., "Ante el anuncio de Cortes Constituyentes", en El País, 23 de septiembre de 1976. Disponible en: https://elpais.com/diario/1976/09/24/opinion/212364007_850215.html

${ }_{53}$ Duverger, M., "Sufragio universal y democracia", conferencia pronunciada el 18 de noviembre de 1976, en VV.AA., Ley Electoral y consecuencias políticas, CITEP, Madrid, 1977, p. 138.

${ }^{54}$ Duverger, M., "Ley electoral y sistema de partidos políticos", Debate posterior a la conferencia pronunciada el 17 de noviembre de 1976, en VV.AA., Ley Electoral y consecuencias políticas, CITEP, Madrid, 1977, p. 118.

Araucaria. Revista Iberoamericana de Filosofia, Política, Humanidades y Relaciones Internacionales, año $23, \mathrm{n}^{\circ} 47$. Segundo cuatrimestre de 2021. Pp. 255-278. ISSN 1575-6823 e-ISSN 2340-2199 https://dx.doi.org/10.12795/araucaria.2021.i47.12 
Gobierno Suárez prefería este sistema, para evitar la tensión dialéctica de las "dos Españas" 55 . De ahí que, al final, el texto recogiese la fórmula proporcional, pero con la expresión que a Lucas Verdú le preocupaba, es decir, incorporando "dispositivos correctores para evitar fraccionamientos inconvenientes de la Cámara". Como se ha puesto de relieve en diversos trabajos, la inclusión de estos mecanismos correctores se produjo tras una negociación entre el Gobierno y el grupo de Alianza Popular en las cortes franquistas, encabezado por Fraga, y cuya posición en este punto defendió Martínez Esteruelas, partidarios del sistema mayoritario y contrarios al proporcional ${ }^{56}$. El hecho de insertar estas correcciones al sistema proporcional fue suficiente para que apoyasen la Ley en la votación decisiva ${ }^{57}$.

A partir del referendo de aprobación de la Ley para la Reforma Política, la interlocución del Gobierno con la oposición se incrementó, y se fueron adoptando medidas muy relevantes en el camino hacia la instauración de la democracia, en la mayor parte de los casos de acuerdo con los grupos políticos opositores. Como se ha apuntado, después del referéndum el ritmo lo marcó el Gobierno Suárez, y la oposición lo respaldaba, al constatar con hechos su firme paso hacia la democracia ${ }^{58}$. Se utilizó con frecuencia el decreto-ley, para evitar tener que acudir a unas Cortes franquistas que, si bien habían respaldado la Ley de Reforma Política, podían plantear dificultades en la aprobación de otras medidas como estas. El deseo de llegar a acuerdos resultó ser un anticipo de lo que luego sería el proceso constituyente. Entre esas medidas estaban las que contribuirían a la legalización de los partidos (Decreto-ley de 8 de febrero de 1977) y los sindicatos (Ley de 30 de marzo de 1977). Pero creo que la más relevante, también de cara al futuro, fue el Decreto-ley de 18 de marzo de 1977 sobre normas electorales. Junto a ello, se suprimió la Secretaría general del Movimiento y comenzaron a firmarse algunos tratados internacionales en materia de Derechos Humanos.

55 Torres del Moral, A., Principios de Derecho Constitucional Español, tomo 1, 6a. edición. Servicio de Publicaciones de la Universidad Complutense, p. 32.

${ }^{56}$ Alianza Popular también quería que fuesen las Cortes quienes elaborasen la ley electoral, y no el Gobierno mediante Decreto-Ley. Aunque, como dicen Pilar y Alfonso Fernández-Miranda, en realidad lo que les preocupaba es que la ley estableciese un sistema mayoritario. Cfr. FernándezMiranda, P. y Fernández-Miranda, A., Lo que el Rey me ha pedido. Torcuato Fernández-Miranda y la reforma politica, p. 265. En las páginas 273 y siguientes se sintetiza en este libro la posición contraria a las fórmulas electorales mayoritarias por parte de Torcuato Fernández-Miranda, combinado con las propias opiniones de los autores del trabajo.

${ }^{57}$ No deja de ser curioso, en todo caso, que se defendiese por Alianza Popular el sistema mayoritario, que era el utilizado en la Segunda República y que, por tanto, servía en buena parte de "antimodelo" para la clase política franquista, y tampoco era bien recibido por la oposición. Cfr. Montero Gibert, J. R., Llera Ramo, F. J. y Torcal Loriente, M., "Sistemas electorales en España: una recapitulación», Revista española de Investigaciones Sociológicas, n. ${ }^{\circ}$ 58, p. 10.

${ }^{58}$ Oñate Rubalcaba, P., Consenso e ideología en la transición politica española, Centro de Estudios Políticos y Constitucionales, Madrid, 1998, págs. 265-267. 
Si bien las normas electorales debían respetar el marco establecido en la Ley para la Reforma Política, había cuestiones importantes por concretar. Por ejemplo, se fijó en dos la cuota mínima de diputados por provincia, además de los que le correspondieran a cada una según su población, y el sistema de elección mayoritario del Senado se corrigió con la introducción del voto limitado, un corrector que buscaba una representación más diversificada en la Cámara Alta. En ambos casos se trata de medidas que han perdurado en el tiempo, hasta nuestros días. El mínimo provincial de dos ha supuesto (y supone) un plus de representación para las provincias menos pobladas, en su mayor parte rurales, y en la otra cara de la moneda, una representación inferior para las más pobladas, que suelen ser las más industriales y económicamente más fuertes.

La Transición Política española fue ante todo un proceso de institucionalización democrática que se abrió paso, bien creando instituciones de nueva planta, bien reformando las existentes. Una de las nuevas instituciones fue precisamente la electoral, que de modo significativo mantiene la definición establecida legalmente antes de la puesta en marcha del proceso de elaboración de la Constitución. La Ley para la Reforma Política puso las bases de la construcción de un régimen electoral en España, complementado por el Decreto Ley Electoral de 18 de marzo de 1977, y que se convirtió en una de las claves principales del advenimiento de la democracia.

El consenso con el que se construyó el régimen electoral español fue crucial para dotarlo de la credibilidad social que hizo posible el advenimiento de la democracia en España, y en esta tarea ha sido decisiva la actuación y el desempeño de la Administración Electoral y, en concreto, la Junta Electoral Central.

A la vez que buena parte de la oposición y los expertos discutían en el Hotel Eurobuilding de Madrid ${ }^{59}$, en las Cortes y fuera de ellas se negociaba entre los distintos sectores del franquismo qué fundamentos del sistema electoral iban a figurar en la Ley. Los tres elementos básicos que se mantuvieron desde el proyecto de ley hasta la misma Constitución de 1978 y que hoy perviven en la LOREG son: un tamaño pequeño del Congreso, la circunscripción provincial y la fórmula electoral proporcional (inicialmente sin correcciones, luego corregida tras la incorporación del mencionado cambio en el trámite parlamentario) ${ }^{60}$.

Los "dispositivos correctores" que se incluyeron tras la negociación con Alianza Popular no fueron los que realmente matizaron la proporcionalidad, puesto que el único que se concretó en la Disposición Transitoria primera ("se fijarán porcentajes mínimos de sufragios para acceder al Congreso") se 1977.

${ }^{59}$ Ley electoral y consecuencias políticas, Centro de Investigación y Técnicas Políticas, Madrid,

${ }^{60}$ Fernández-Miranda Lozana, Pilar y Fernández-Miranda Campoamor, Alfonso, Lo que el Rey me ha pedido. Torcuato Fernández-Miranda y la reforma política, p. 276.

Araucaria. Revista Iberoamericana de Filosofí, Política, Humanidades y Relaciones Internacionales, año $23, \mathrm{n}^{\circ} 47$. Segundo cuatrimestre de 2021. Pp. 255-278. ISSN 1575-6823 e-ISSN 2340-2199 https://dx.doi.org/10.12795/araucaria.2021.i47.12 
tradujo en la barrera electoral del 3\% que no ha tenido ninguna influencia en los resultados electorales en los cuarenta años de democracia (solo de modo puntual en Madrid). Los elementos que sí actuaron como "correctores" de la proporcionalidad fueron y son otros: (i) la circunscripción provincial; (ii) el tamaño reducido del Congreso, que trae consigo una mayoría de circunscripciones pequeñas; (iii) la asignación de un mínimo provincial de dos escaños por provincia, que provoca una sobrerrepresentación de las circunscripciones con menos habitantes ${ }^{61}$.

$\mathrm{Si}$ bien no todos los elementos del sistema electoral están en la Constitución, lo cierto es que se han constitucionalizado muchos de ellos, más que en otros países de nuestro entorno, y también que incluso los aspectos que se regulan en la Ley Orgánica del Régimen Electoral General pueden considerarse "materialmente constitucionales", en el sentido afirmado por Fernández-Miranda: "están en el centro de cualquier Constitución política por tratarse de normas referidas nada menos que a las reglas del juego para la legítima conquista del poder"62. Por este motivo, son normas que deben aprobarse y modificarse con niveles de acuerdo y consenso superiores a otro tipo de regulaciones, y deben también mantenerse estables en sus elementos sustanciales. Esos que, precisamente, fueron fijados en la Ley para la Reforma Política, complementados por el Real Decreto-Ley de 1977 y llevados posteriormente, en buena parte, a la propia Constitución, y en lo demás, a la LOREG.

No voy a extenderme más sobre los efectos del sistema electoral y las propuestas de reforma que nunca han llegado a buen puerto: me he ocupado del asunto en otros lugares ${ }^{63}$; ahora me interesa destacar precisamente la estabilidad, el buen funcionamiento y el respeto al régimen electoral como institución que ha dado credibilidad a nuestro sistema democrático. A esta credibilidad no solamente ha contribuido el buen funcionamiento del sistema y la fórmula electoral, sino el de la Administración electoral, en sentido amplio: todos los organismos que se han ocupado de organizar los procesos electorales (Departamentos de Interior, Presidencia o Justicia de la Administración central o autonómica; Oficina del Censo Electoral, Sociedad Estatal de Correos y Telégrafos) y aquellos que velan por la limpieza del proceso y resuelven en primera instancia las reclamaciones (juntas electorales) o quienes resuelven en vía judicial los posibles conflictos (tribunales ordinarios de la jurisdicción contencioso-administrativa o Tribunal Constitucional).

${ }^{61}$ Sobre esta cuestión, vid. Torres del Moral, Antonio, "La reforma del sistema electoral o la cuadratura del círculo", en Revista de Derecho Político, núm. 74, 2009, pp. 60-63.

62 Fernández-Miranda Campoamor, Alfonso, "Reflexiones sobre una improbable reforma del sistema electoral del Congreso de los Diputados", en Revista de Derecho Político, núm. 74, 2009, p. 23 .

${ }^{63}$ Vid., por todos, Vidal Prado, Carlos, El sistema electoral español. Una propuesta de reforma, Método ediciones, Granada, 1995.

Araucaria. Revista Iberoamericana de Filosofía, Política, Humanidades y Relaciones Internacionales, año $23, \mathrm{n}^{\circ} 47$. Segundo cuatrimestre de 2021. Pp. 255-278. ISSN 1575-6823 e-ISSN 2340-2199 https://dx.doi.org/10.12795/araucaria.2021.i47.12 
El detalle sobre la Administración electoral se concretó inicialmente en el Real Decreto-ley 20/1977, de 18 de marzo, sobre Normas Electorales. Supuso una novedad institucional, en la medida en que implicó la creación de una serie de instancias presididas y supervisadas por la Junta Electoral Central que, si bien engarzaba con algunos precedentes en la historia constitucional española, adquiría un carácter plenamente democrático y abriría una página inédita en nuestra política presidida por el buen hacer. Ello permitió algo que parecía imposible en aquel momento en nuestro país: que los españoles $-\mathrm{y}$ sobre todo la oposición política al franquismo- vieran factible un proceso electoral limpio, en el que los resultados tradujeran lealmente el sentir social sin fraudes ni falsificaciones, algo que nuestro imaginario colectivo negaba como un imposible metafísico.

Sobre la base de esta realidad institucional y de la labor de la Administración electoral se ha levantado un régimen electoral que cumple sobradamente con todas las exigencias democráticas. Más allá de cuáles sean las características del modelo electoral español, las juntas electorales, y singularmente la Junta Electoral Central, cumple con tres notas necesarias para definir una institución: (i) su carácter permanente; (ii) su dominio de los acontecimientos; su neutralidad; (iii) su sistema de provisión mixta y su obrar por consenso en la inmensa mayoría de las ocasiones permite que sus acuerdos se impongan con autoridad no contestada y, como regla general, acatada.

¿Por qué me he querido detener en esta cuestión? Porque también hoy se escuchan desde movimientos populistas críticas al funcionamiento del sistema, se cuestionan por ejemplo la gestión del voto por correo, el escrutinio de las mesas electorales y los resultados oficiales determinados en el escrutinio general, incluso la labor de las juntas electorales. Pero asistimos de nuevo a un ejercicio de desinformación, en el que las redes sociales tienen mucha relevancia, que debería ser contrarrestado con una información seria y rigurosa sobre las numerosas garantías que ofrece nuestro régimen electoral, cuya credibilidad nunca se ha puesto en duda y sobre el cual nunca ha podido probarse la más mínima irregularidad. Por lo tanto, tenemos una institución estable, respetada, que ha desempeñado un papel fundamental en la estabilidad de nuestro sistema democrático, y que lo ha hecho desde los inicios, en la propia transición política, y legitimando ya las primeras Cortes Generales democráticas que se convirtieron en constituyentes.

A la legitimación de esas primeras elecciones contribuyó de manera decisiva otro hecho que ya he apuntado con anterioridad: la legalización del Partido Comunista de España. Sobre esto se ha escrito también mucho, y no voy a extenderme demasiado. Solo quiero apuntar que es otro ejemplo de la valentía y la audacia de Adolfo Suárez, sin duda con el apoyo del Rey, y que demuestra -en contra de lo que muchos dicen hoy- que en este proceso 
no estaba sometido a los condicionantes que pudiera oponer el Ejército. O, al menos, que esos condicionantes no eran tan rígidos o graves como para impedir pasos en firme como el que dio para completar el mapa político de las candidaturas en esas elecciones (si bien es cierto que también pudo haber un cálculo político, pues la participación del PCE iba a suponer una división del voto en la izquierda y restaría peso al PSOE). Además, hay que tener en cuenta que tomó la decisión a pesar de la posición un tanto ambigua de Estados Unidos, que con Ford y Kissinger había estado más bien en contra, y con Carter y Cyrus Vance no parecía tampoco que fuese una pretensión muy firme; al menos no tenían prisa ${ }^{64}$.

\section{Proceso constituyente y conclusiones}

Lo que antes de la aprobación de la Ley para la Reforma Política eran contactos más o menos directos y ocasionales con la oposición democrática al franquismo, se convirtieron en una relación fluida y constante con esos grupos por parte del Gobierno, del propio Adolfo Suárez y sus colaboradores. A ello contribuyó, sin duda, el cambio de actitud de la mayoría de la oposición, que se dio cuenta de la férrea voluntad democrática del Presidente del Gobierno, y de que éste, a la vista de los resultados del referéndum, gozaba de un respaldo social abrumador. Ya hemos apuntado algunos hitos en los meses posteriores a la aprobación de la Ley, pero evidentemente el reto mayor lo representaban las primeras elecciones democráticas de junio de 1977. Lo que estaba ocurriendo en España asombraba a Europa y al mundo, porque nadie esperaba una evolución tan rápida de los acontecimientos.

Lo que sucedió después de las elecciones del 77, con el inicio de los trabajos para aprobar una Constitución de modo inmediato, puso de relieve que la voluntad de reconciliación y acuerdo no era algo pretendido solamente por una parte, la que procedía del franquismo, sino también por la otra, la que había luchado contra la dictadura. Por razones de espacio y porque queda ya poco por decir sobre esta época, no me extenderé en relatar el proceso constituyente: me limitaré a hacer varias referencias a algunas aportaciones recientes.

Si se me permite, me gustaría remitir al lector a las breves páginas escritas por uno de los padres de la Constitución, José Pedro Pérez Llorca, en el capítulo titulado “¿Balance o liquidación?”, dentro del libro España constitucional (1978-2018). Trayectorias y perspectivas. Es la última descripción publicada sobre el método de trabajo de la Ponencia constitucional, y singularmente recomiendo el segundo apartado: "El método del consenso". Ahí se refleja un

${ }^{64}$ Powell, Ch. T., "La dimensión exterior de la transición española", en Revista CIDOB d'Afers Internacionals 26. Política Exterior y Seguridad en España, 1993, p. 43.

Araucaria. Revista Iberoamericana de Filosofia, Política, Humanidades y Relaciones Internacionales, año $23, \mathrm{n}^{\circ} 47$. Segundo cuatrimestre de 2021. Pp. 255-278. ISSN 1575-6823 e-ISSN 2340-2199 https://dx.doi.org/10.12795/araucaria.2021.i47.12 
espíritu, una calidad política, humana y profesional, que permitieron alcanzar un resultado excelente. También se pone de relieve cómo, además de los 7 miembros de la Ponencia, hubo actores muy relevantes, y con generosidad Pérez Llorca afirma: "quien esto escribe no puede dejar de rendir un homenaje de gratitud emocionada a la intervención, decisiva en esta fase, de Fernando Abril Martorell. Junto con Alfonso Guerra, escenificó el consenso, negociando también con los ponentes, que resultaban ser siempre los redactores de los textos finales (...), y con los dirigentes políticos, los textos aparcados y las cuestiones irresueltas" "65. Se consiguió, así, en muy breve tiempo, un texto constitucional que "no nació contra nadie", elaborado con "espíritu de integración"66, nacido del consenso ${ }^{67}$, y que nos ha proporcionado los mejores años de nuestra historia democrática. Más de cuarenta años después, deberíamos aspirar a acometer la necesaria reforma constitucional con el mismo espíritu integrador y con un nivel de consenso lo más parecido posible.

Para poder compartir un proyecto común hemos de partir de nuestra verdadera historia, seguir el camino que nos dejaron marcado nuestros mayores, adaptando el texto constitucional a los nuevos tiempos y corrigiendo los defectos que se han manifestado. Pero para hacerlo así, hay que tener memoria. Y, por desgracia, nuestro Estado democrático ha puesto escaso celo "en crear y difundir una simbología propia y unos «lugares de memoria» asociados a aquella experiencia singular" vivida en la transición, que se nos ha transmitido más bien a través de las experiencias individuales de algunos de sus protagonistas, pero no desde el punto de vista colectivo: "la memoria colectiva de la transición sigue siendo un misterio impenetrable". Son expresiones de Fuentes Aragonés, que sostiene además lo siguiente: "resulta muy difícil saber incluso en qué medida existe una memoria común de aquella experiencia colectiva, más allá de las memorias sectoriales que corresponden a las distintas ideologías, territorios o grupos sociales" ${ }^{68}$.

Lo que se está pretendiendo en los últimos tiempos no parece que vaya en la buena dirección. La "memoria histórica" se fija solamente en la República,

\footnotetext{
${ }^{65}$ Pérez Llorca, José Pedro, “Balance o liquidación?”, en Pendás, Benigno (dir.) España constitucional (1978-2018). Trayectorias y perspectivas, Centro de Estudios Políticos y Constitucionales, Madrid, 2018, tomo I, p.59.

${ }^{66}$ Este es el carácter que subraya Miguel Herrero R. de Miñón en su colaboración en el mismo libro mencionado: "Espíritu de integración”, en Pendás, Benigno (dir.) España constitucional (19782018). Trayectorias y perspectivas, Centro de Estudios Políticos y Constitucionales, Madrid, 2018, tomo I, pp. 43-52.

${ }^{67}$ Otro padre de la Constitución, Roca Junyent, Miguel, es el aspecto que subraya en "Cuarenta años después”, en Pendás, Benigno (dir.) España constitucional (1978-2018). Trayectorias y perspectivas, Centro de Estudios Políticos y Constitucionales, Madrid, 2018, tomo I, pp. 69-78. También resalta esta característica Alfonso Guerra en su contribución al mismo libro, ya citada en la nota al pie de página núm. 3 .

68 Juan Francisco Fuentes Aragonés, "Lo que los españoles 1laman la transición”, en Mélanges de la Casa de Velázquez, núm. 36-1, 2006. Disponible en: http://journals.openedition.org/mcv/2359 DOI : https://doi.org/10.4000/mcv.2359
}

Araucaria. Revista Iberoamericana de Filosofia, Política, Humanidades y Relaciones Internacionales, año $23, \mathrm{n}^{\circ} 47$. Segundo cuatrimestre de 2021. Pp. 255-278. ISSN 1575-6823 e-ISSN 2340-2199 https://dx.doi.org/10.12795/araucaria.2021.i47.12 
la Guerra civil y el franquismo. Es una especie de reproche más o menos explícito a la transición, que supuestamente sacrificó la memoria histórica en aras de la reconciliación. Pero es un reproche sesgado, unilateral, que olvida lo más importante de esa época: el espíritu de reconciliación, de perdón, de acogida, de integración. No es una memoria integradora, sino al revés; no es conciliadora, sino que pretende dividir de nuevo en dos Españas. Supone desandar el camino recorrido, para reconstruir de modo erróneo y desviado lo que tanto tiempo costó alcanzar. Representa una vuelta atrás para enmendar la plana a los protagonistas de aquellos años, queriendo llevar a cabo en el siglo XXI la ruptura que meritoriamente se evitó entre 1975 y 1978, emprendiendo el sendero de la reforma, una reforma cuyo resultado fue tan asombroso que ni siquiera los rupturistas hubieran soñado con él.

\section{Bibliografía}

Areilza, J.M., Diario de un ministro de la Monarquía, Planeta, 1977.

Carr, Raymond, El rostro cambiante de Clio: Ensayos. España-Gran Bretaña, Biblioteca Nueva, Madrid, 2005,

Casas Pardo, J., "La transición política española a la democracia. Un enfoque de Public Choice”, en Historia Contemporánea, núm. 27, 2003, págs. 869-906

Castellà Andreu, J.M., "1978-2018: la Constitución del consenso en crisis", en Letras Libres, diciembre 2018, disponible en; https://www.letraslibres.com/espana-mexico/ politica/1978-2018-la-constitucion-del-consenso-en-crisis

Cavero, I., "Soberanía popular y elecciones para constituyentes", en Informaciones Políticas, Revista semanal de Política nacional y extranjera, núm. 69, 18 de septiembre de 1976

Cebrián, E., Contreras Casado, M., "La ley para la Reforma Política: memoria y legitimidad en los inicios de la transición española a la democracia", en Revista de Estudios Políticos (nueva época), Núm. 168, Madrid, abril-junio (2015), págs. 77-114.

De Esteban, J., Varela, S., García Fernández, F.J., López Guerra, L., García Ruiz, J.J., Desarrollo Político y Constitución Española, Ariel, Barcelona, 1973.

De Esteban. Jorge, "Proyecto de unas bases constitucionales para España", en Pendás, Benigno (dir.) España constitucional (1978-2018). Trayectorias y perspectivas, Centro de Estudios Políticos y Constitucionales, Madrid, 2018, tomo I, págs. 193218.

Duverger, M., "Ley electoral y sistema de partidos políticos", conferencia pronunciada el 17 de noviembre de 1976, en VV.AA., Ley Electoral y consecuencias políticas, CITEP, Madrid, 1977, págs. 101-126.

Duverger, M., "Sufragio universal y democracia", conferencia pronunciada el 18 de noviembre de 1976, en VV.AA., Ley Electoral y consecuencias políticas, CITEP, Madrid, 1977, págs. 127-146.

Fernández-Miranda Campoamor, C., "Consideraciones en torno a los antecedentes de la transición política española”, En Boletín de la Facultad de Derecho UNED, núms. $8-9,1995$ 
Fernández-Miranda, P. y Fernández-Miranda, A., Lo que el Rey me ha pedido. Torcuato Fernández-Miranda y la reforma política, Plaza y Janés, 1995.

Fernández-Miranda Campoamor, Alfonso, "Reflexiones sobre una improbable reforma del sistema electoral del Congreso de los Diputados", en Revista de Derecho Político, núm. 74, 2009, pág. 23.

Fuentes Aragonés, Juan Francisco, "Lo que los españoles llaman la transición", en Mélanges de la Casa de Velázquez, núm. 36-1, 2006. Disponible en: http://journals. openedition.org/mcv/2359 DOI : https://doi.org/10.4000/mcv.2359

García López, E., "Apuntes para una relectura heterodoxa de la transición política española”, en Estudios de Deusto, Vol. 61/1, Bilbao, Enero-Junio 2013, págs. 127153

García López, E., El Poder Constituyente Evolutivo en la Crisis de la Modernidad Política, Universidad Javeriana, Bogotá 2011

García San Miguel, L., Teoría de la Transición. Un análisis del modelo español, 19731978, Editora Nacional, Madrid, 1981

Guerra, Alfonso, "La Constitución del consenso", en Pendás, Benigno (dir.) España constitucional (1978-2018). Trayectorias y perspectivas, Centro de Estudios Políticos y Constitucionales, Madrid, 2018, tomo I, págs.

Hernández Sánchez, A., "La opinión pública española en la transición del franquismo a la democracia", Revista de Investigaciones Políticas y Sociológicas, Vol. 9, núm. 1, 2010, págs. 39-69

Miguel Herrero R. de Miñón en su colaboración en el mismo libro mencionado: "Espíritu de integración", en Pendás, Benigno (dir.) España constitucional (1978-2018). Trayectorias y perspectivas, Centro de Estudios Políticos y Constitucionales, Madrid, 2018, tomo I, págs. 43-52.

Linz, J.J., Montero, J.R., Crisis y cambio: electores y partidos en la España de los años ochenta, Centro de Estudios Constitucionales, 1986

López Pintor, R. "El estado de la opinión pública española y la transición a la democracia", en Revista Española de Investigaciones Sociológicas, núm. 13, 1981, págs. 7-47.

López Pintor, R. "El estado de la opinión pública española y la transición a la democracia", en Revista Española de Investigaciones Sociológicas, núm. 13, 1981,

Lucas Verdú, P., La octava Ley Fundamental. Crítica jurídico-politica de la Reforma Suárez, Tecnos, Madrid, 1976.

Molinero Ruiz, C., "Treinta años después, la transición revisada", en Molinero Ruíz, Carmen (Ed.), La transición treinta años después, Barcelona, Península, 2006, págs. 9-26.

Montero Gibert, J. R., Llera Ramo, F. J. y Torcal Loriente, M., "Sistemas electorales en España: una recapitulación», Revista española de Investigaciones Sociológicas, n. ${ }^{\circ}$ 58, pág. 10 .

Montero, J.R., "Sobre la democracia en España: legitimidad, apoyos institucionales y significados", Estudios = Working papers / Instituto Juan March de Estudios e Investigaciones, Centro de Estudios Avanzados en Ciencias Sociales 1992/39. Disponible en: https://digital.march.es/fedora/objects/fjm-pub:799/datastreams/ $\underline{\mathrm{OBJ} / \text { content }}$

Montero, M., Rodríguez-Virgili, J., García-Ortega, C., "La construcción mediática de la comunidad política. La prensa en la transición española a la democracia”, en Palabra Clave, vol. 11, núm. 3, diciembre 2008, págs. 293-309 
Ollero, C., "El Contexto Político de unas Elecciones en España" (conferencia pronunciada el 18 de noviembre de 1976), en VV.AA., Ley Electoral y consecuencias políticas, CITEP, Madrid, 1977, págs. 1-18.

Oñate Rubalcaba, P., Consenso e ideología en la transición política española, Centro de Estudios Políticos y Constitucionales, Madrid, 1998.

Pérez Llorca, José Pedro, “Balance o liquidación?”, en Pendás, Benigno (dir.) España constitucional (1978-2018). Trayectorias y perspectivas, Centro de Estudios Políticos y Constitucionales, Madrid, 2018, tomo I,

Powell, Ch. T., "La dimensión exterior de la transición española", en Revista CIDOB d'Afers

Internacionals 26. Política Exterior y Seguridad en España, 1993

Ramírez, M., España. 1939-1975. Régimen político e ideología. Ed. Labor. Barcelona 1978

Roca Junyent, Miguel, es el aspecto que subraya en "Cuarenta años después", en Pendás, Benigno (dir.) España constitucional (1978-2018). Trayectorias y perspectivas, Centro de Estudios Políticos y Constitucionales, Madrid, 2018, tomo I, págs. 69-78.

Tajadura Tejada, J., "La reforma constitucional como problema", en Estudios Culturales Hispánicos, 1 / 2020, págs. 91-113.

Torres del Moral, A., Constitucionalismo histórico español, 9ª edición, Ed. Universitas, Madrid, 2018

Torres del Moral, A., Principios de Derecho Constitucional Español, tomo 1, 6a . edición. Servicio de Publicaciones de la Universidad Complutense, 2010.

Torres del Moral, Antonio, "La reforma del sistema electoral o la cuadratura del círculo", en Revista de Derecho Político, núm. 74, 2009, págs.

Tusell. J., La transición española a la democracia, Publicado por Historia 16, 1991.

Vidal Prado, Carlos, El sistema electoral español. Una propuesta de reforma, Método ediciones, Granada, 1995 